\title{
Gastric emptying of a solid meal is accelerated by the removal of dietary fibre naturally present in food
}

L Benini, G Castellani, F Brighenti, K W Heaton, M T Brentegani, M C Casiraghi, C Sembenini, N Pellegrini, A Fioretta, G Minniti, M Porrini, G Testolin, I Vantini

\begin{abstract}
Exogenous fibre added to liquid meals delays gastric emptying. Its effect on solid meals is uncertain, and nothing is known of the effect on gastric emptying of fibre naturally present in food. This study therefore looked at gastric emptying of two different solid meals in eight healthy subjects and their blood glucose responses. The meals were exactly equivalent except for the total dietary fibre content (high fibre $20 \mathrm{~g}$, low fibre $4 \mathrm{~g}$ of dietary fibre per $1000 \mathrm{kcal})$ and supplied $870 \mathrm{kcal}$ (700 kcal women), $47 \%$ of which was from carbohydrates, $36 \%$ from fats, and $17 \%$ from proteins. Ultrasonography was used to measure antral diameters before the meal (basal), immediately after it (time 0 ), and at $30,60,120,180,240$, and 300 minutes. In addition, subjects filled in a questionnaire on their feelings of hunger, epigastric fullness, and satiety before the meal and at hourly intervals after it. Basal and maximal postprandial antral sections were similar for the two meals (basal section: 283.9 (29.5) $v$ 340.9 $(44 \cdot 7) \mathrm{mm}^{2}$ for the low and the high fibre meal, NS; maximal postprandial section: $1726(101.9) \quad v 1593(120.4) \mathrm{mm}^{2}$, NS). Total gastric emptying time was significantly reduced by fibre removal $(\mathbf{1 8 6 . 0}$ $(15 \cdot 6) v 231 \cdot 7(17 \cdot 3)$ minutes after the low and the high fibre meal, $p<0 \cdot 05)$. Blood glucose was higher after the low fibre meal, and the area under the glycaemic curve significantly greater $(226(23 \cdot 1) v$ $\left.160(20.0) \mathrm{mmol} / \mathrm{min} / \mathrm{dl}^{-1}, p<0 \cdot 05\right)$. No difference was found in satiety or fullness feelings, but hunger returned more rapidly after the low fibre meal. In conclusion, fibre naturally present in food delays gastric emptying of a solid meal, reduces the glycaemic response, and delays the return of hunger.

(Gut 1995; 36: 825-830)
\end{abstract}

Keywords: gastric emptying, dietary fibre, solid meal.

Dietary fibre has a number of metabolic effects, some of which are potentially useful in treating pathological conditions such as obesity, hypercholesterolaemia, and diabetes. ${ }^{1}$ It has been shown that soluble fibre can reduce the plasma glucose response to meals ${ }^{2-4}$ and slow down the return of hunger. ${ }^{5-7}$ These actions are considered to be caused, at least in part, by the slowing down effect of dietary fibre on gastric emptying. This has been clearly shown for liquid meals. In fact, it has been repeatedly shown that pectin and guar gum delay the gastric emptying of glucose solutions, reducing the glycaemic response, ${ }^{8-13}$ and that this delay is mediated, at least in short term experiments, by the increase in viscosity of gastric contents. ${ }^{1415}$ The relation between postprandial glycaemia and gastric emptying is more complex when liquid starch is ingested, as other factors, such as the susceptibility to $\alpha$-amylase, ${ }^{16}$ play a part. The effect of fibre on solid meals is even more controversial. Different authors report a delayed, 111718 normal $^{19-22}$ or accelerated ${ }^{23}$ gastric emptying when purified fibre is added to the meal. Also wheat bran has been reported to accelerate the emptying of liquid ${ }^{24}$ but not of semisolid or solid ${ }^{25-27}$ meals. Many hypotheses may be put forward to explain these different results, such as peculiar properties of the exogenous fibre tested (solubility, viscosity, water holding capacity), or the different methods used to hydrate the fibre itself or to label meal constituents. ${ }^{28}$ Methods have been suggested to label fibre, but whereas this permits accurate measurement of the gastric emptying of fibre, ${ }^{2629}$ it gives no idea of the fate of the whole meal. Even less clear is the effect on gastric emptying of dietary fibre naturally present in food. Most of the studies so far available on the metabolic effects of natural fibre were carried out by introducing into the meal, one at a time, starches of various sources, obviously different not only in fibre content, but also in other properties. We are aware of only two relevant experiments using meals naturally high and low in cereal fibre but otherwise equivalent. One was a pioneering experiment in 1953 comparing wholemeal and brown bread, spread with barium paste. ${ }^{30}$ In each of six volunteers the barium took longer to leave the stomach when given with the wholemeal bread. The methodology was crude (half hourly $x$ rays) and the meals unnatural. Grimes and Goddard ${ }^{31}$ found that after white bread the liquid phase emptied faster than after wholemeal but there was no difference with the solid phase. Again, the meals were atypical. Structurally intact food rich in fibre, such as fruit and vegetables, may be emptied more slowly because of a greater resistance to antral grinding activity or to the action of hydrolytic enzymes. This could explain why the consumption of fruit juice compared with whole fruit is associated with greater metabolic 
Composition of the high and low fibre test means (grams)

\begin{tabular}{|c|c|c|c|c|c|c|}
\hline \multirow[b]{2}{*}{ Constituent } & \multicolumn{3}{|l|}{ High fibre } & \multicolumn{3}{|c|}{ Low fibre } \\
\hline & Form & Males & Females & Form & Males & Females \\
\hline Pasta & Wholemeal & 73 & 58 & White & 73 & 58 \\
\hline Tomato & Puree & 100 & 80 & Juice & 95 & 72 \\
\hline \multicolumn{7}{|l|}{ Hamburger } \\
\hline Ground beef & & 100 & 80 & & 100 & 80 \\
\hline Crumbs & Wholemeal & 45 & 36 & White & 40 & 32 \\
\hline Carrots & Minced & 150 & 120 & Juice & 145 & 116 \\
\hline Olive oil & & 27 & 22 & & 27 & 22 \\
\hline Oranges & Homogenised & 150 & 120 & Juice & 120 & 96 \\
\hline
\end{tabular}

responses ${ }^{5}$ and suggests that the disruption of food form, rather than removal of fibre in itself, may be important in modifying gastric emptying. ${ }^{32}$

The aims of this study were therefore to clarify the effect of dietary fibre naturally present in food on (a) gastric emptying; (b) glycaemic response; (c) feelings of hunger, satiety, and epigastric fullness, using realistic meals.

\section{Methods}

Subjects

Eight healthy asymptomatic volunteers (five males; age range 28-41 years), mean (SEM) body mass index $21.5(1 \cdot 0)$, taking no drugs, took part in the study after having given informed consent. Women were always studied during the preluteal part of their period. Subjects were asked to adhere to a list of low fibre - low glycaemic index foods the evening before each experiment.

\section{Meals}

After an overnight fast, all subjects ate two test meals, on different days and in random order. Meals were presented as a two course solid meal, exactly equivalent except for the total dietary fibre content (high fibre, $20 \mathrm{~g}$; low fibre, $4 \mathrm{~g}$ dietary fibre per $1000 \mathrm{kcal}$ ). The Table gives the composition of the meal.

For the high fibre meal, wholemeal pasta (Maccheroni Integrali, Barilla, Italy) was boiled for 12 minutes in $0.5 \% \mathrm{NaCl}$ and then minced to particles of about $5 \mathrm{~mm}$. It was dressed with $10 \mathrm{~g}$ of raw oil and tomatoes reduced to a puree in a food processor. Hamburgers were prepared mixing minced beef with wholemeal breadcrumbs and cooked for six minutes on a hot non-stick plate. Raw carrots were minced in a food processor and dressed with the remaining oil and with salt ad libitum. Oranges were peeled and homogenised to give a thick juice.

For the low fibre meal, white pasta (Maccheroni, Barilla, Italy) was prepared as for the high fibre meal, then dressed with $10 \mathrm{~g}$ raw oil and tomato juice, obtained by centrifuging tomato puree into a domestic food processor equipped with a $0.3 \mathrm{~mm}$ screen (Braun Multipratic). The same centrifuge was used to obtain clear carrot and orange juice, which were mixed to prevent oxidation of the carrot juice and used as a drink. The remaining raw oil was added to the hamburger, prepared as for the high fibre meal but using white instead of wholemeal bread crumbs. Total dietary fibre and nutrient composition of the single ingredients of both meals were analysed using the Prosky ${ }^{33}$ and AOAC methods ${ }^{34}$ respectively. The meals supplied $870 \mathrm{kcal}(700$ kcal women), $47 \%$ of which was from carbohydrates, $36 \%$ from fats, and $17 \%$ from proteins.

The final meal volumes were $717 \mathrm{ml}$ for the high fibre and $672 \mathrm{ml}$ for the low fibre meal. The volumes were adjusted by varying the amount of water permitted. Subjects were instructed to eat in 20 minutes, drinking and chewing as they pleased. Meals were prepared in the experimental kitchen at the Department of Food Sciences using the same batch of ingredients. They were divided into individual portions in plastic containers, sealed under $\mathrm{N}_{2} / \mathrm{CO}_{2}$ atmosphere, and kept frozen until use. Meals were reheated in an oven just before the study.

\section{Gastric emptying}

Real time ultrasonography was used to measure gastric antrum diameters ${ }^{35}$ before the meal (basal), immediately after it (time 0 ), and at $30,60,120,180,240$, and 300 minutes. All measurements were performed by the same operator (GC). The mean of three readings was calculated at each time during interperistaltic relaxation. The antral cross sectional area was calculated assuming an elliptical shape.

Ultrasound measurement of complete gastric emptying had been found to parallel the results of radiological and scintigraphic methods. ${ }^{35} 36$ The time required for the return of antral size to the baseline after a solid meal ('total emptying time') can be divided into two periods: in the first the antral sections remain fairly constant ('lag phase'), in the second they gradually decrease to the baseline. This behaviour resembles the scintigraphic sequence of solid emptying but, in our view, represents different aspects of gastric emptying. The echographic 'lag phase' does not represent the period before emptying begins, as it does in scintigraphic studies, but rather a period during which the antrum is transporting gastric contents but maintains its size because it is continuously fed by the fundic reservoir. In support of this view is the fact that, when two of our volunteers ate increasing quantities of pudding on different days, their antral cross sectional areas increased linearly to a maximum, after 400 and $500 \mathrm{ml}$ meals, but failed to increase further after 700 and $900 \mathrm{ml}$ meals. Moreover, when three controls ate a standard solid meal ( $800 \mathrm{kcal}, 15 \%$ from proteins, $45 \%$ from fats, $40 \%$ from carbohydrates) and, on a different day, a meal with the same composition but twice the size, the 'lag phase' was prolonged from $30 \cdot 4-50$ to $120-150$ minutes, with no difference in the slope of the rapid phase of antral emptying (unpublished data). The phase of 'rapid emptying' begins when no food is left in the fundus, and continues while the antrum progressively returns to its fasting state. 


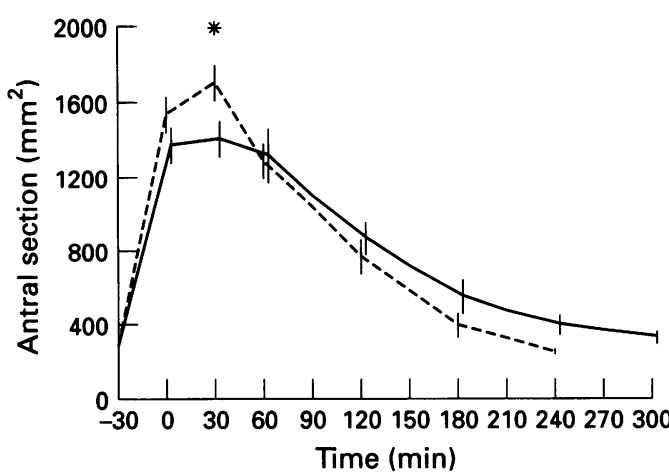

Figure 1: Mean antral cross sectional areas during the study period after ingestion of the high fibre (continuous line) and of the low fibre meal (dotted line). Vertical bars represent mean (SEM). ${ }^{\star} p<0.05$.

In this study, the following parameters were considered: basal and maximal cross sectional antral section, time required for total emptying, per cent retention of the meal at hourly intervals, slope of the emptying curve during the rapid phase of antral emptying, and duration of the 'lag phase'. Total emptying time was defined as the time required for the return of antral cross sectional area to the fasting values. It was calculated from the regression equation for antral areas against time, considering only the time interval from the maximal value to the return to baseline. This method is more accurate and objective than simply measuring the time to return to baseline. The slope of the emptying curve was obtained from the same regression equation. The 'lag phase' was calculated by extrapolating the regression line to zero time, as previously suggested for the scintigraphic method. ${ }^{37}$ The per cent of the meal retained in the stomach at each time was calculated by relating the increase in antral cross sectional area to the maximal postprandial increase.

Interassay variation of the different parameters was evaluated by performing the study twice in nine controls and calculating the mean coefficient of variation. This was found to be $6.7 \%$ for the maximal section, $9 \cdot 1 \%$ for the basal section and the total emptying time, and $16.3 \%$ for the per cent of the meal emptied after 120 minutes.

Whole blood glucose was measured in finger prick samples before and $0,30,60,90$, and 120 minutes after finishing the meal, using an enzymatic glucosidase method.

Subjects filled in a questionnaire on their

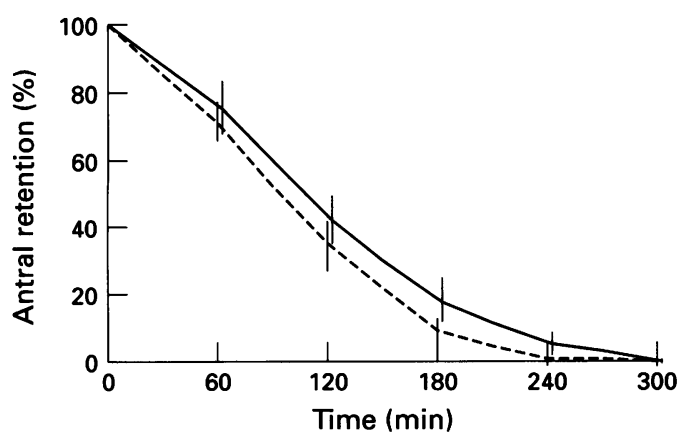

Figure 2: Change with time of the per cent of the meal retained in the antrum (see Fig 1). The difference between the two meals was not statistically significant.

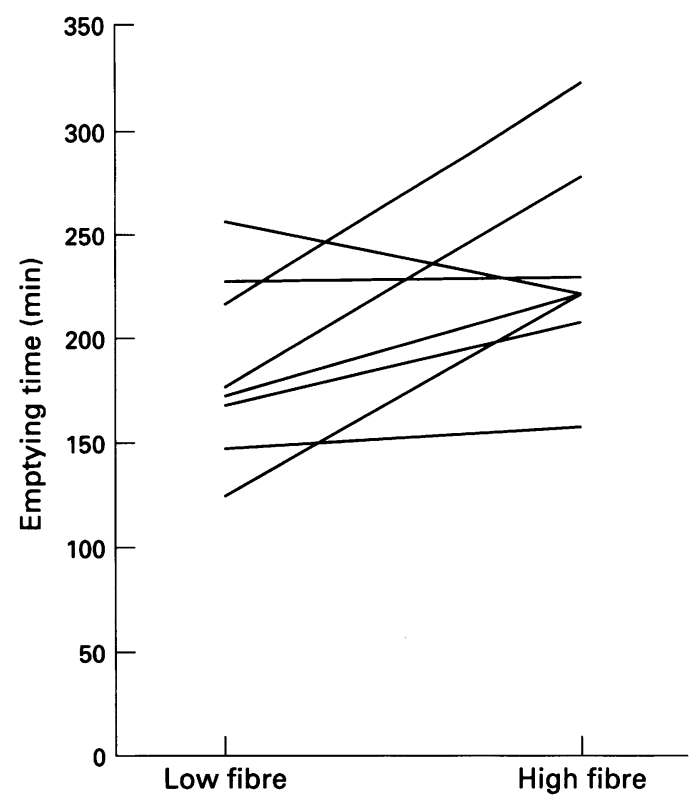

Figure 3: Time required for total gastric emptying of the high fibre and of the low fibre meal in the individual subjects.

feelings of hunger, epigastric fullness, and satiety before the meal and at $0,30,60,120$, 180,240 , and 300 minutes. Each feeling was rated on a triangle, the base of which corresponded to the maximum and the apex to the minimum of the feeling. Results were expressed in $\mathrm{cm}^{2}$ from the apex (maximum possible value $\left.22 \cdot 5 \mathrm{~cm}^{2}\right) .38$

\section{Statistics}

Results are given as mean (SEM). The statistical significance of differences between paired results was calculated using Student's $t$ test or the Wilcoxon signed ranks test, as appropriate.

\section{Results}

Figure 1 shows the change with time of the antral cross sectional areas. Basal and maximal postprandial cross sectional areas were similar for the two meals (basal: 283.9 (29.5) $v 340.9$ $(44.7) \mathrm{mm}^{2}$ for the low and the high fibre meal, NS; maximal postprandial area: $1726(101.9)$ $v 1593(120 \cdot 4) \mathrm{mm}^{2}$, NS). The apparent difference in the figure between the mean values of maximal cross sectional areas after the two meals is because this maximal value was reached in the studied subjects at different times. The maximal antral distension was seen slightly earlier after the low fibre meal. A significant difference in antral sections was found only at time $30(1708(102 \cdot 3) v 1410$ $(101.8) \mathrm{mm}^{2}$ for the low and the high fibre meal, $\mathrm{p}<0 \cdot 02$ ).

Figure 2 shows the change with time of the per cent of the meal retained in the antrum. There was a trend towards lower antral retention after the low fibre meal, but at no point was this statistically significant.

Figure 3 shows the total emptying time in the individual subjects. Gastric emptying was significantly shortened by fibre removal $(186.0$ $(15.6) v 231.7(17.3)$ minutes after low and high fibre, $p<0.05)$. The total emptying was 


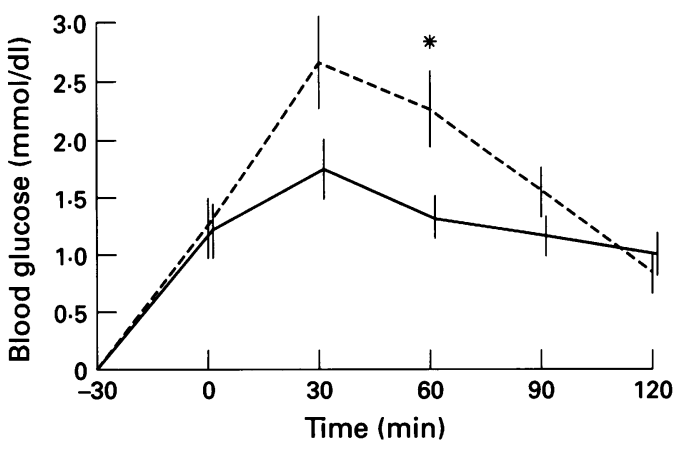

Figure 4: Capillary blood glucose before and at half hourly intervals after the two meals (see Fig 1).

slightly prolonged only in one subject. In another subject the emptying curve changed, after the low fibre meal, to the negative exponential curve of liquid meals. The calculated 'lag phase' was not statistically different after the two meals $(42(10 \cdot 3) v 52(15 \cdot 8)$ minutes, NS).

Figure 4 shows the glycaemic concentrations over time. A rise in blood glucose was already present after both meals at time 0 (that is, 20 minutes after the start of the meal), well before the end of the lag phase. Blood glucose was higher after the low fibre meal from 30 minutes, the increase being statistically significant at 60 minutes. The area under the glycaemic curve was statistically greater after the low fibre meal $(226(23 \cdot 1) v 160(20 \cdot 0)$ $\left.\mathrm{mmol} / \mathrm{min} / \mathrm{dl}^{-1}, \mathrm{p}<0.05\right)$.

No difference was found in satiety or epigastric fullness. There was a quicker return of hunger, however, after the low fibre meal (Fig 5), the difference in hunger rating being statistically significant at 120 and 180 minutes.

\section{Discussion}

This study confirms that fibre naturally present in food has an effect both on gastric emptying and on the metabolic and sensory effects of the meal. After the fibre depleted meal, antral areas were significantly greater but then reverted to the basal value more quickly than after the fibre preserved meal.

Gastric handling of solid food seems, therefore, to be considerably affected by dietary fibre from its earliest phases. This effect was evident after a single meal, which is not consistent with a commonly accepted hypothesis for fibre action on the stomach, namely, that when fibre arrives in the distal ileum or in the colon, it exerts a negative feedback (the 'ileal brake'). ${ }^{39-43}$

Another explanation for the slowing down effect of fibre on gastric emptying is greater resistance of fibre containing food to the grinding action of the antrum. Disruption of food form, rather than removal of fibre in itself, might be important in modifying gastric emptying. ${ }^{32}$ Evidence for such a phenomenon was found in a study on the plasma glucose and insulin responses to a meal of varied consistency (spaghetti, rice, French bread, mashed potatoes) labelled with technetium-99malbumin. ${ }^{44} \mathrm{~A}$ clear relation was found between the gastric emptying rate and the maximum change in glucose and insulin concentrations. The most cohesive food (spaghetti) produced a flattened response, the least cohesive one (mashed potatoes) a sharp increase above the baseline. In our opinion, this hypothesis does not fully explain our results, as all food constituents were pre-ground to a small particle size, and unlimited chewing was permitted. Consequently, swallowed particles must have been always below the size (1-2 mm) for which a sieving antral action is seen ${ }^{45}$; no further grinding should therefore have been required to accelerate their passage in the duodenum. In effect, O'Dea et al showed that polished and unpolished rice meals, once ground, elicit a comparable glycaemic response, which is far greater than the corresponding unground meals. ${ }^{46}$

It could be that the fibre rich meal had a greater viscosity in the stomach, which delayed intragastric movement of the meal toward the antrum. ${ }^{1415}$ No formal measurement was obtained of the bolus viscosity just before swallowing. This would have been very difficult to do and interpret, as the different meal courses were kept separate and not homogenised, so as to mimic the normal setting of a Mediterranean diet. Increased viscosity, however, has so far been shown to delay gastric emptying only of liquid but not of solid meals. In contrast, the increased viscosity of gastric contents caused by fibre has been reported to speed up the emptying of solid particles, such as light Teflon spheres, which otherwise float away from the gastric outlet. ${ }^{45}$ The impression of all our volunteers was that the consistency of the two meals, apart from carrots, was very similar. Moreover, the time required for the consumption of the two meals was kept constant, ruling out longer gastric filling induced by fibre as the explanation for the differences in emptying. 5

A more probable explanation for our findings is delayed absorption of fats induced by the presence of fibre in the meal, ${ }^{324748}$ as it has been shown that fat present in the small bowel delays gastric emptying to a degree proportional to the length of the small bowel exposed to it. ${ }^{49}$

It may seem surprising that a small bowel effect of fibre, in terms of blood glucose concentrations, after the two meals was already evident (though statistically not significant), as early as $\mathbf{3 0}$ minutes after the end of the meal, which is well before the end of the 'lag phase'.

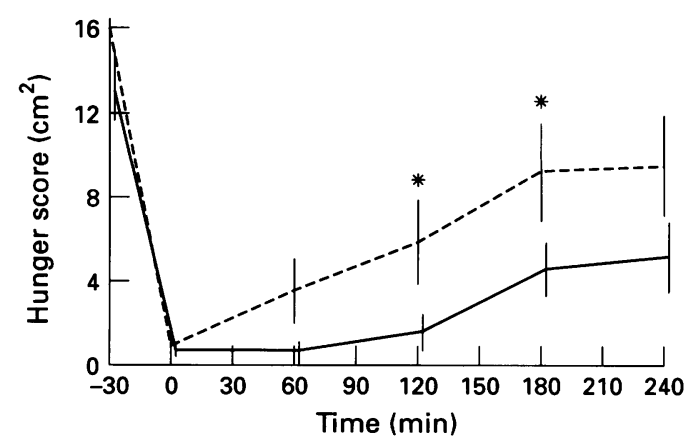

Figure 5: Scores for the feeling of hunger before and at hourly intervals after the two meals (see Fig 1). ${ }^{\star} p<0 \cdot 03$. 
However, the echographic 'lag phase' does not represent the period preceding the start of gastric emptying, as sometimes suggested for its scintigraphic counterpart ${ }^{5051}$ but rather the period during which food is continuously delivered by the gastric fundal 'reservoir' to the antrum, which persists therefore at its maximal dilatation. Gastric contents start to enter the duodenum immediately after arrival of food in the stomach, even before the start of antral grinding. ${ }^{29}$

Whatever the mechanism of the delayed gastric emptying, this delay is the most probable explanation for the flattened glucose response after the fibre rich meal. Other mechanisms can explain the low glycaemic response to foods rich in fibre and in slowly digestible starches, such as legumes. For example, Bornet et al ${ }^{16}$ showed that in vitro digestibility was the only factor related to the glycaemic response after the ingestion of foods with different susceptibility to $\alpha$-amylolysis; differences in viscosity or in gastric emptying had no effect on the glycaemic response. Other authors have shown, however, that wholemeal bread and pasta are equivalent to their white counterparts both in terms of glycaemic index and in vitro digestibility. ${ }^{52} 53$ As the starch components of our meals were bread and pasta, it is unlikely that differences in starch digestibility had any role in the different glycaemic response to the meals.

In conclusion, this study shows that fibre naturally present in food can delay gastric emptying of a solid meal, even after a single fibre rich meal. It can reduce the glycaemic response to the meal and delay the return of hunger, without any effect on satiety and on epigastric fullness feelings. The gastric and metabolic effects of food processing, which reduces the quantity of fibre naturally present in food must be carefully considered.

The authors are grateful to Mrs Carol Thomas-Bulighin for reviewing the English. This work was supported by grant 93.00599.PF41 from the Italian National Research Council (CNR)-Targeted Project 'Prevention and Control of Disease Factors', subproject 'Alimentation'. Part of these data have
previously been presented to the British Society of Gastroenterology (Gut 1994; 35 (suppl 5): S55).

1 Miranda PM, Horowitz DL. High-fibre diets in the treatment of diabetes mellitus. Ann Intern Med 1978; 88: ment 6 .

2 Jenkins DJA, Leeds AR, Gassull MA, Wolover TMS, Goff DV, Alberti KGMM, et al. Unabsorbable carbohydrates and diabetes: decreased postprandial hyperglycaemia. Lancet 1976; ii: 172-4.

3 Jenkins DJA, Leeds AR, Gassull MA, Cochet B, Alberti KGMM. Decrease in postprandial insulin and glucose concentrations by guar and pectin. Ann Intern Med 1977 86: $20-3$.

4 Munoz JM, Sandstead HH, Jacob RA. Effects of dietary fiber on glucose tolerance of normal men. Diabetes 1979; 28: 496-502.

5 Haber GB, Heaton KW, Murphy D, Burroughs LF. Depletion and disruption of dietary fiber: effects on satiety, plasma glucose and serum insulin. Lancet 1977; ii: satiety,

6 Bolton RP, Heaton KW, Burroughs LF. The role of dietary fiber in satiety, glucose, and insulin: studies with fruit and fiber in satiety, glucose, and insulin: studies
fruit juice. Am $\mathscr{f}$ Clin Nutr 1981; 34: 211-7.

7 Bergmann JF, Chassany O, Petit A, Triki R, Caulin C, Segrestaa JM. Correlation between echographic gastric emptying and appetite: influence of psyllium. Gut 1992 33: $1042-3$.

8 Holt S, Heading RC, Carter DC, Prescott LF, Tothill P. Effect of gel fibre on gastric emptying and absorption of glucose and paracetamol. Lancet 1979; i: 636-9.

9 Flourie B, Vidon N, Chayvialle JA, Palma R, Franchisseur C, Bernier JJ. Effect of increased amounts of pectin on solid-liquid meal digestion in healthy man. Am $\mathcal{f}$ Clin Nutr 1985; 42: 495-503.
10 Schwartz SE, Levine RA, Singh A, Scheidecker JR, Track NS. Sustained pectin ingestion delays gastric emptying. Gastroenterology 1982; 83: 812-7.

11 Sandhu KS, El Samahi MM, Mena I, Dooley CP Valenzuela JE. Effect of pectin on gastric emptying and gastroduodenal motility in normal subjects. Gastrogastroduodenal motility in
enterology 1987; 92: 486-92.

12 Whilmhurst $\mathrm{P}$, Crawley JCW. The measurement of gastric transit time in obese subjects using ${ }^{24} \mathrm{Na}$ and the effects of energy content and guar gum on gastric emptying and energy content and guar gum
satiety. $B r \mathcal{F}$ Nutr $1980 ; 44: 1-6$.

13 Tadesse $\mathrm{K}$. The effect of dietary fibre isolates on gastric secretion, acidity and emptying. Br $\mathcal{f}$ Nutr 1986; 55: 507-13.

14 Hunt JN. The viscosity of a test meal. Its influence on gastric secretion and emptying. Lancet 1954; i: 17-8.

15 Jenkins DJA, Wolower TMS, Leeds AR, Gassull MA, Haisman P, Dilawari J, et al. Dietary fibres, fibre analogues and glucose tolerance: importance of viscosity. BMF 1978; 1: 1392-4.

16 Bornet FRJ, Bizais Y, Bruley Des Varannes S, Pouliquen B Delort Laval J, Galmiche JP. $\alpha$-Amylase (EC 3. 2. 1. 1.) susceptibility rather than viscosity or gastric emptying rate controls plasma responses to starch in healthy humans. $\mathrm{Br}$ f Nutr 1990; 63: 207-20.

17 Di Lorenzo C, Cardiff MW, Hajnal F, Valenzuela JE. Pectin delays gastric emptying and increases satiety in obese subjects. Gastroenterology 1988; 95: 1211-5.

18 Brown NJ, Worlding J, Rumsey RDE, Read NW. The effect of guar gum on the distribution of a radiolabelled meal in the gastrointestinal tract of the rat. Br $\mathcal{F}$ Nutr 1988; 59: 223-32.

19 Rainbird AL. Effect of guar gum on gastric emptying of test meals of varying energy content in growing pigs. Br $\mathcal{f}$ Nutr 1986; 55: 99-109.

20 Rainbird AL, Low AG. Effect of various types of dietary fibre on gastric emptying in growing pigs. $\operatorname{Br} \mathcal{F}$ Nutr 1986; 55: $111-21$.

21 Meyer JH, Mayer EA, Jehn D, Gu Y, Fink AS, Fried M. Gastric processing and emptying of fat. Gastroenterology 1986; 90: 1176-87.

22 Rydning A, Nesland A, Berstad A. Influence of fibre on postprandial intragastric juice acidity, pepsin and bile acids in healthy subjects. Scand $¥$ Gastroenterol $1984 ; 19$; 1039-44.

23 Potkins ZV, Lawrence TLJ. Studies on the effects of composition and physical form of the diet on gastric abnormalities and nutrient utilization in the growing pig. Animal Production 1984; 38: 534 .

24 Kasper H, Eilles C, Reiners C, Schrezenmeir J. The influence of dietary fiber on gastric transit time. Hepatogastroenterology 1985; 32: 69-71.

25 Rydning A, Berstad A, Berstad T, Hertzenberg L. The effect of guar gum and fiber-enriched wheat bran on gastric emptying of a semisolid meal in healthy subjects. Scand f Gastroenterol 1985; 20: 330-4.

26 Sagar S, Grime JS, Little W, Patten M, Gulliford P, Critchley $M$, et al. Technetium-99m labelled bran: a new agent for measuring gastric emptying. Clin Radiol 1983; 34: $275-8$.

27 Madar Z, Odes HS. The role of dietary fiber in gastroduodenal disorders. In: Paoletti R, ed. Dietary fiber duodenal disorders. In: Paoletti R, ed. Dietary fiber
research. Progress in biochemical pharmacology. Vol 24. research. Progress in biochemical

28 Low AG. Nutritional regulation of gastric secretion, digestion and emptying. Nutr Res Rev 1990; 3: 229-52.

29 Carryer PW, Brown ML, Malagelada JR, Carlson GL McGall JT. Quantification of the fate of dietary fiber in humans by a newly developed radiolabeled fiber marker. Gastroenterology 1982; 82: 389-94.

30 McCance RA, Prior KM, Widdowson EM. A radiological study of the rate of passage of brown and white bread through the digestive tract of man. Br $\mathcal{f}$ Nutr 1953; 7: 98-105.

31 Grimes DS, Goddard J. Gastric emptying of wholemeal and white bread. Gut 1977; 18: 725-9.

32 Leeds AR. Modification of intestinal absorption by dietary fiber and fiber components. In: Vahouny GV, Kritchevsky $\mathrm{D}$, eds. Dietary fiber in health and disease. New York: Plenum Press, 1982: 53-71.

33 Prosky L, Asp NG, Furda I, Devries JW, Schweizer TF, Harland BF. Determination of total dietary fiber in foods, food products and total diets: interlaboratory study. f Assoc Off Anal Chem 1984; 67: 1044-9.

34 AOAC. Official methods of analysis. 12th ed. Washington DC, Association of Official Analytical Chemists, 1975 35 Bolondi L, Bortolotti M, Santi M, Caletti T, Gaiani S, Labò G. Measurement of gastric emptying time by real-time G. Measurement of gastric emptying time by rea
ultrasonography. Gastroenterology 1985; 89: 752-9.

36 Marzio L, Giacobbe A, Conoscitore P, Facciorusso D, Frusciante V, Modoni S. Evaluation of the use of ultraFrusciante $V$, Modoni $S$. Evaluation of the use of ultra-
sonography in the study of liquid gastric emptying. $A m$

37 Siegel Ja, Urbain J-L, Adler LP, Charkes ND, Maurer AH, Krevsky B, et al. Biphasic nature of gastric emptying. Gut 1988; 29: 85-9.

38 Turconi G, Bazzano R, Caramella R, Crovetti R, Porrini $M$. High-calorie fibre-rich breakfast: its effect on satiety. fournal of Human Nutrition and Dietetics 1993; 6: 245-52. 39 Lin HC, Moller NA, Wolinsky MM, Kim BH, Doty JE, Meyer JH. Sustained slowing effect of lentils on gastric emptying of solids in humans and dogs. Gastroenterology 1992; 102: 787-92.

40 Lin HC, Kim BH, Elashoff JD, Doty JE, Gu Y-G, Meyer $\mathrm{JH}$. Gastric emptying of solid food is most potently 
inhibited by carbohydrate in the canine distal ileum. Gastroenterology 1992; 102: 793-801.

41 Jain NK, Boivin M, Zinsmeister AR, Brown MI Malagelada JR, DiMagno EP. Effect of ileal perfusion of carbohydrates and amylase inhibitor on gastrointestinal hormones and emptying. Gastroenterology 1989; 96; 377-87.

42 Stephen A, Cummings J. Mechanism of action of dietary fiber in the human colon. Nature 1980; 284: 283-4.

43 Fleming SE. Influence of dietary fiber on the production, absorption, or excretion of short chain fatty acids in humans. In: Spiller GA, ed. Handbook of dietary fiber in humans. In: Spiller GA, ed. Handbook of dietary fiber in

44 Mourot J, Thouvenot P, Couet C, Antoine JM, Krobicka A, Debry G. Relationship between the rate of gastric emptying and glucose and insulin responses to starch foods in young healthy adults. Am $\mathcal{f}$ Clin Nutr 1988; 48: 1035-40.

45 Meyer JH, Thomson JB, Cohen MB, Shadchehr A, Mandiola SA. Sieving of solid food by the canine stomach and sieving after gastric surgery. Gastroenterology 1979; 76: 804-13.

46 O'Dea K, Nestel PJ, Antonoff L. Physical factors influencing postprandial glucose and insulin responses to starch. Am $\mathcal{f}$ Clin Nutr 1980; 33: 760-5.
47 Ebihara K, Schneeman BO. Interaction of bile acids, phospholipids, cholesterol and triglyceride with dietary fiber in the small intestine of rats. F Nutr 1989; 119: 1100-6.

48 Cassidy MM, Calvert RJ. Effects of dietary fiber on intestinal absorption of lipids. In: Spiller GA, ed. Handbook of dietary fiber in human nutrition. Boca Raton: CRC Press, 1993: 153-62.

49 Lin HC, Doty JE, Reedy TJ, Meyer JH. Inhibition of gastric emptying by sodium oleate depends on length of intestine

50 Tothill P, McLoughlin GP, Heading RC. Techniques and errors in scintigraphic measurements of gastric emptying. $f$ Nucl Med 1978; 19: 256-61.

51 Moore JG, Christian PE, Taylor AT, Alazraki N. Gastric emptying measurements: delayed and complex emptyin patterns without appropriate correction. $\mathcal{F}$ Nucl Med 1985; 26: 1206-10

52 Jenkins DJA, Wolever TMS, Taylor RH, Barker HM, Fiender H, Gassul MA. Lack of effect of refining on the lycemic response to cereals. Diabetes Care 1981; 4: 509-13.

53 Jenkins DJA, Ghafari $H$, Wolever TMS, Taylor RH, Jenkins AL, Barker HM, et al. Relationship between rate of digestion of foods and post-prandial glycaemia. Diabetologia tion of foods and 